\title{
Optical interferometry techniques in electrochemistry education
}

\author{
Khaled Habib
}

Khaled J. Habib, "Optical interferometry techniques in electrochemistry education," Proc. SPIE 3831, Sixth International Conference on Education and Training in Optics and Photonics, (16 June 2000); doi:

10.1117/12.388742

Event: Education and Training in Optics and Photonics (ETOP'99), 1999, Cancun, Mexico 


\title{
Optical Interferometry Techniques in Electrochemistry Education
}

\author{
K.Habib \\ Materials Application Department \\ KISR,P.O.BOX 24885 SAFAT, 13109 Kuwait
}

\begin{abstract}
In the present investigation, an optical transducer has been developed for materials testing and evaluation of different electrochemical phenomena. The optical transducer was developed by incorporating methods of holographic interferometry for measuring microscopic deformation and electrochemical techniques for determining the corrosion current of metallic samples in aqueous solutions. In addition, the optical transducer was applied not only as an electrometer for measuring different electrochemical parameters but also, the optical transducer was applied as a 3D-interferometric microscope for detecting different micro-alterations at a metal surface in aqueous solution at a microscopic scale.
\end{abstract}

Keywords: Optical Transducer, Uniform Corrsion, Localized Corrosion, Corrosion Current Densities, Holographic Interferometry, Optical Corrosion-Meter, Stress Corrosion Cracking, Corrosion Fatigue, Double Layer Capacitance, Alternating Current Impedance.

\section{INTRODUCTION}

The author developed an optical transducer in 1988 for materials testing and evaluation of different electrochemical phenomena. The optical transducer was developed based on incorporating methods of holographic interferometry for measuring microscopic deformations and electrochemical techniques for determining electrochemical parameters of samples in aqueous solutions. In addition, the optical transducer was applied not only as an electrometer for measuring different electrochemical parameters but also, the optical transducer was applied as a 3D-interferometric microscope for detecting different micro-alterations at a metal surface in aqueous solution, at a microscopic scale. Initially, the optical transducer was used to determine the mechanochemical behaviors of metals in aqueous solution, i.e., stress corrosion cracking, corrosion fatigue, and hydrogen embrittlement $1-5$. Determinations of the mechanochemical behaviors of mertals in aqueous solutions, was based on detecting micro-deformations and measuring the corresponding current density by the optical transducer. Further more, the optical transducer was applied as an optical corrosion-meter $6-8$ for measuring cathodic deposit and anodic dissolution layers of metals in aqueous solutions. Also, the optical corrosion-meter was utilized to determine the cathodic and anodic current densities which correspond to the cathodic deposit and anodic dissolution layers, respectively. The cathodic and anodic current densities were measured electromagnetically by the optical transducer, rather than electronically by one of the classical methods, i.e, an Ammeter, of measuring the flow of the electronic current in a conductor. In addition, the optical transducer was applied to measure uniform corrosion and localized corrosion on metal surfaces and on substrates covered by organic coatings or crevice assemblies ${ }^{8-14}$. The optical transducer also,was used to document adsorption and desorption phenomena of chemical species on metal surfaces in aqueous solutions ${ }^{12}$. Finally ,the optical transducer was applied as an electrometer for measuring the double layer capacitance, the alternating current impedance and the corresponding oxide layer thickness of metals in aqueous solution 15-16. Details examples on the above applications of the optical transducer in electrochemistry will be given in the presentation. 


\section{REFERENCES}

1.Habib K.J. , Holographic interferometry of a polarized and loaded metallic electrodes in aqueous solution, Applied Optics, 29 (13), pp.867-869, 1990.

2.Habib K.J., Initial behavior of corrosion fatigue/hydrogen embrittlement of metallic electrodes in aqueous solutions, Experimental Techniques of Physics, 38 (5/6), pp. 535-538, 1990.

3. Habib K.J., Carmichael G., Lakes R. , Stwalley W. , Novel technique for measuring stress corrosion cracking of metallic electrodes in aqueous solutions: Theory and applications. Corrosion Journal 49 (5), pp.354-362, 1993.

4 . Habib K.J., Initiation of stress corrosion cracking of $\mathrm{Ti} 90-\mathrm{Al}_{6}-\mathrm{V}_{4}$ wire in aqueous solution: Non- destructive monitoring by holographic interferometry, Optics and Lasers in Engineering, 20, pp.81-85, 1994.

5. Habib K.J., Non-Destructive Evaluation of Metallic Electrodes Under Corrosion Fatique Conditions by Holographic Interferometry, Optics and Lasers in Engineering, 23,pp.65-70, 1995.

6 .Habib K.J., Holograhic interferometry in predicting cathodic deposition of metals in aqueous solution., Proc. SPIE, 1230 , pp. 293-6, 1990.

7. Habib K.J., "Model of holographic interferometry of anodic dissolution of metals in aqueous solution',Optics and Lasers in Engineering. 18, , pp.115-20, 1993.

8. K.Habib, F. Al Sabti, and H. Al- mazeedi, "Optical Corrosion -Meter" Optics and Lasers in Engineering,Vol.27, No.2,PP.227-233, 1997.

9. K.Habib, "Non-destructive Evaluation of An Epoxy -Based Coating by Optical Interferometry Techniques" Optics and Lasers in Engineering,Vol.23, No.2,PP.213-219, 1995.

10.K.Habib, F. Al Sabti,"Interferometric Sensor for Electrochemical Studies of Metallic Alloys in Aqueous Solution" OPTICAL REVIEW,Vol.4, No.2,PP.324-328, 1997.

11. K.Habib and F.Al-Sabti," Monitoring Pitting Corrosion by Holographic Interferometry", Corrosion Journal, 53.(9) PP. 680-685, 1997.

12. K.Habib," In-Situ Monitoring of Pitting Corrosion of Stainless Steel by Optical Interferometry", ELECTROCHEMICA Acta, accepted for Publication, in press, 1999.

13.K.Habib," Detection of Localized Corrosion of Copper Alloys by Holographic Interferometry", Corrosion Science, 40.(8) PP. 1435-1440, 1998.

14.K.Habib,"Crevice Corrosion of Copper Alloys by Optical Interferometry", Optics and Lasers in Engineering Vol.31,PP.13-20, 1999.

15.K.Habib,"Measurement of the Double Layer Capacitance of Aluminium Samples by Holographic Interferometry",Optics and Laser Technology, Vol.28,No.8,1996,PP.579-584.

16.K.Habib,"Measurement of the a.c.Impedance of Aluminium Samples by Holographic Interferometry",Optics and Lasers in Engineering Vol.28, PP.37-46, 1997. 